\title{
Maximizing lifetime egg production in a Wadden Sea population of the tellinid bivalve Macoma balthica: a trade-off between immediate and future reproductive outputs
}

\author{
J. J. Beukema*, J. Drent, P. J. C. Honkoop** \\ Netherlands Institute for Sea Research, PO Box 59, 1790 AB Den Burg, Texel, The Netherlands
}

\begin{abstract}
The number of eggs produced in the annual spawning season by an adult female Macoma balthica (L.) of Wadden Sea origin increases in a non-linear manner with increasing shell length and body weight. It depends primarily on the weight-at-length immediately before spawning. Lean individuals with a low body-mass index (BMI) of $5.6 \mathrm{mg} \mathrm{cm}^{-3}$ or less spawn no eggs. Gamete output increases to about one-third of soft-body weight (in the order of 100000 eggs) at the maximal BMIs observed $\left(\sim 15 \mathrm{mg} \mathrm{cm}^{-3}\right)$. Long-term monitoring ( $\left.>20 \mathrm{yr}\right)$ of densities of a Wadden Sea M. balthica population revealed that survival to the spawning season of the next year declined from about $65 \%$ at higher-than-average values of BMI $\left(>8 \mathrm{mg} \mathrm{cm}^{-3}\right)$ to about $30 \%$ at the lowest values of BMI observed (5 to $\left.6 \mathrm{mg} \mathrm{cm}^{-3}\right)$. Annual growth was also significantly lower in years starting with a low $\mathrm{BMI}$ value. Because spawning lowers body weight and thus the BMI, spawning is bound to reduce subsequent survival rates and body-weight increments. Thus, a trade-off situation exists between immediate and future spawning outputs. The consequences for total lifetime egg production of various levels of gamete output at first spawning (at an age of $2 \mathrm{yr}$ ) were estimated by model calculations, starting from a wide range of body weights at a standard length. The model results realistically predict that maximal lifetime egg production can be achieved only if $M$. balthica refrain from spawning at BMIs below a certain threshold value (viz. $\sim 6 \mathrm{mg} \mathrm{cm}^{-3}$, which is close to their actual threshold of $5.6 \mathrm{mg} \mathrm{cm}^{-3}$ ) and if their spawning output increases with weight-at-length (again in a manner close to what actually happens). It is concluded that $M$. balthica populations in the Wadden Sea apply a spawning strategy adapted to the local conditions.
\end{abstract}

KEY WORDS: Annual survival $\cdot$ Optimal strategy $\cdot$ Reproductive investment $\cdot$ Wadden Sea

\section{INTRODUCTION}

In long-lived organisms that can potentially reproduce more than once in their lifetime, the investments made at first or current reproduction will inevitably lead to lower reproductive outputs during future reproduction (Houston \& McNamara 1999). Such trade-off between immediate and future reproductive efforts can originate from increased mortality risks or declined growth rates following high reproductive outputs. To achieve maxi-

\footnotetext{
*E-mail: janb@nioz.nl

** Present address: Marine Ecology Laboratory, A 11, University of Sydney, New South Wales 2006, Australia
}

mal fitness, i.e. maximal lifetime reproduction, any advantage of high immediate reproductive output should counterbalance later losses and any loss of low immediate output should be counterbalanced by better prospects for reproductive activities later in life. In the tuning of first reproductive output, the pre-spawning condition of the animal will play a role: the higher the amounts of reserve and gamete material gathered, the more weight loss at spawning the animal can afford without endangering its subsequent survival and growth. For example, blue mussels with low energetic contents experienced much higher post-spawning mortality than adjacently living mussels which had spawned less extensively (Myrand et al. 2000). 
In the case of the bivalve Macoma balthica (L.) populations in the Wadden Sea, first spawning takes place in early spring at a shell length of 10 to $15 \mathrm{~mm}$ (i.e. generally at an age of $2 \mathrm{yr}$ ). At an average annual survival of about $60 \%$ in adult $M$. balthica (Beukema 1980, van der Meer et al. 2000), high proportions of the individuals spawn in subsequent years as well. At spawning, they can lose a high proportion of their body weight (de Wilde \& Berghuis 1978, Honkoop \& van der Meer 1997). If low body weights negatively affect subsequent survival and growth, any high spawning output will result in a reduction in the probability and magnitude of future reproduction. In other words, $M$. balthica would be in a trade-off situation at spawning.

There is some evidence that adult female Macoma balthica living in the Wadden Sea adapt their spawning outputs to their condition at spawning. Lean individuals do not spawn at all, and females with average weight-at-length spawn fewer eggs than heavier individuals (Honkoop \& van der Meer 1997, Honkoop et al. 1999). As a proportion of total soft-body mass before spawning, the egg mass spawned increases with increasing weight-at-length from 0 to $\sim 30 \%$. The question posed in the present paper is: Does this tuning of spawning output to body-weight condition represent an optimal spawning strategy (in the sense of ensuring a maximal lifetime number of eggs per individual female)? To approach this question, we developed a model to calculate the consequences for total lifetime egg production of variation in reproductive output at first spawning by individuals varying in weight-atlength. Most data needed for this model were obtained from a long-term (start 1970) sampling program of several $M$. balthica populations in the westernmost part of the Wadden Sea (viz. annual growth in units of length and weight, variability in weight-at-length, annual survival). Data on egg production (over a range of ash-free dry weight and weight-at-length) were derived from both experimental and field studies (Honkoop \& van der Meer 1997).

\section{MATERIALS AND METHODS}

Field observations were made at Balgzand, a $50 \mathrm{~km}^{2}$ tidal-flat area in the westernmost part of the Wadden Sea, located at about $53^{\circ} \mathrm{N}$ and $5^{\circ} \mathrm{E}$. A long-term monitoring program of the benthic macrofauna started in the early 1970s, including twice-annual quantitative sampling at 15 fixed stations scattered over Balgzand (for location of individual stations: see Fig. 2 of Beukema 1993). The stations covered all types of sediments and the entire intertidal depth range of about $1.4 \mathrm{~m}$. Details of the distribution of Macoma balthica over Balgzand can be found in Beukema (1993). Data were used from samples taken in late winter, mostly in March, i.e. just before the annual spawning season in April. In $M$. balthica, the following parameters were obtained: numbers $\mathrm{m}^{-2}$ for each age class, shell length for each individual, and ash-free dry weight (AFDW) of the soft parts for each mm length group within each age class. From the AFDW data of each length group, we calculated an index for weight-at-length, also called 'condition index' (Bonsdorff \& Wenne 1989) or (Honkoop \& Beukema 1997) body-mass index (BMI) as: $\mathrm{BMI}=\mathrm{AFDW} / L^{3} \mathrm{mg} \mathrm{cm}{ }^{-3}$, in which $L^{3}$ is the third power of the shell length along its longest axis. From these individual BMI values for each mm length group, a weighted average per year class was calculated for each sampling station and at each sampling occasion (once per year in late winter). Survival was calculated from successive estimates of numerical density of individual year classes at 13 stations, and the numbers found at these stations were summed to obtain an annual Balgzand estimate (the data of the 2 northernmost stations in an exposed area with invariably low M. balthica numbers were excluded). Because annual survival of $M$. balthica in the eastern part of Balgzand suddenly declined after 1991, the use of data on numerical densities was limited to the samplings between 1972 and 1991.

Numbers and sizes of spawned eggs were determined in individual females originating from the field (collected in March on Balgzand) or from experiments in which body weights were manipulated during winter by water temperatures and daily feeding time (Honkoop \& Beukema 1997), as described in Honkoop \& van der Meer (1997). As there is no shell growth in winter (Lammens 1967, Beukema 1980), weight changes in winter are directly expressed in changes in BMI values. After spawning, gonads were microscopically checked and only egg counts from nearly empty females were used. Egg mass was calculated from egg number and mean egg diameter. In March to June 1999, adult Macoma balthica were frequently collected at 3 intertidal sites in the western Wadden Sea and these individuals were dissected to obtain separate estimates of changes in AFDW of gonads and somatic tissue during the spawning season.

\section{RESULTS}

\section{Characteristics of the Balgzand Macoma balthica population}

Growth in length and weight

Annual rates of growth in length declined with time above an age of $1 \mathrm{yr}$, following roughly a von Berta- 


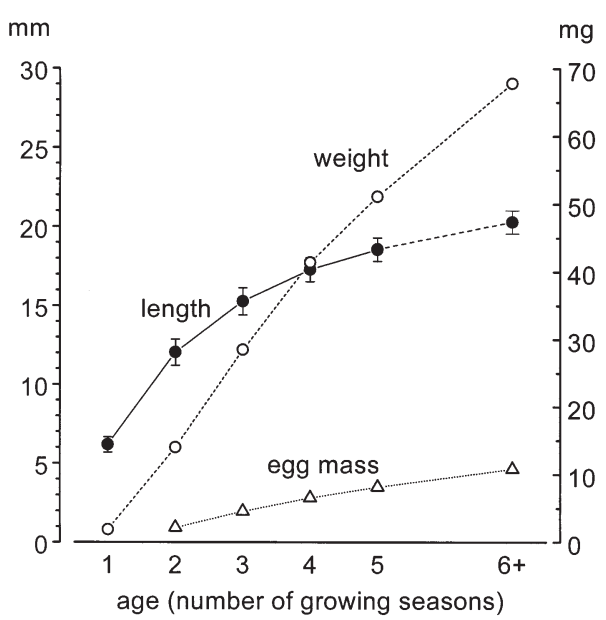

Fig. 1. Macoma balthica. Average growth for population at Balgzand. Continuous line: mean $( \pm 1 \mathrm{SD})$ length at successive ages in March at 15 stations and over 30 yr (1970 to 1999), showing year-to-year variation in annual 15-station means $(n=30)$. From mean lengths, ash-free dry weights (AFDW) of soft parts (right-hand vertical axis) were calculated as $W=8 \times$ $L^{3}$ (i.e. a close-to-average weight-at-length). Egg masses were calculated as $16 \%$ of AFDW (i.e. mean proportion of

AFDW spawned at a body-mass index of $8 \mathrm{mg} \mathrm{cm}^{-3}$ )

lanffy-type pattern (continuous line in Fig. 1). AFDWs of the soft parts increased with time in the usual S-shaped pattern. Annual (March to March) increases were between 10 and $15 \mathrm{mg}$ AFDW during the second to fifth year (Fig. 1). Because of uncertainties in year-mark reading in individuals of $>5 \mathrm{yr}$, we present detailed data only for the first $5 \mathrm{yr}$ of life, and combine all data on the (rare) older individuals (6+ in Fig. 1).

Weight of the annual egg masses (spawned in April) amounted to an average of $16 \%$ of the weight of the soft-body parts (Honkoop et al. 1999); therefore, the mean weight of spawned egg masses increases with age in a way similar to the total weights of the soft parts; i.e. almost linearly over the first few years of reproduction from $\sim 2 \mathrm{mg}$ at first spawning (age $2 \mathrm{yr}$ ) to $\sim 10 \mathrm{mg}$ in the oldest individuals (Fig. 1).

Annual growth rates of Macoma balthica vary significantly on Balgzand, depending in particular on spring concentrations of planktonic diatoms (Beukema \& Cadée 1991). During the growth season following first spawning, the mean length increment for the 13 stations ranged from a minimum of 1.6 to a maximum of $5.1 \mathrm{~mm}$ during the $28 \mathrm{yr}$ of the 1970 to 1998 period of observation. In particular after the 5 coldest winters of this period, length increments were substantially higher (ranging from 3.9 to $4.4 \mathrm{~mm}$ ) than the long-term average of $3.3 \mathrm{~mm}$. Growth was further exceptionally large (viz. $5.1 \mathrm{~mm}$ ) in 1991 after a winter and spring with exceptionally high phytoplankton concentrations (Beukema \& Cadée 1996).

Compared to other regions, the Macoma balthica population at Balgzand showed rapid growth and high maximum length and weight values. This is in accordance with its geographic location $\left(53^{\circ} \mathrm{N}\right)$, as Beukema \& Meehan (1985) observed maximum values of growth and size around $50^{\circ} \mathrm{N}$.

\section{Weight-at-length}

At the age of first spawning (generally between 10 and $15 \mathrm{~mm}$ ), mean BMI amounted to $8.1 \mathrm{mg} \mathrm{cm}^{-3}$ (data from 13 stations and $30 \mathrm{yr}$ : 1970 to 1999, inclusive). These data were collected as part of the annual late-winter sampling program, and represent prespawning values. The spread of the individual yearclass-group observations was substantial; the standard deviation of the above mean amounted to 1.6. However, BMI values $<6.0$ were rare $(<3 \%$ of 379 observations) as were values $\gtrsim 12$ (Fig. 2).

BMI values were not dependent on age. Mean Balgzand values (30 yr, 13 stations) for successive age groups (nearly 2, 3, 4, 5, and 6+ yr) were 8.1, 8.3, 8.2, 8.1, and 7.7, respectively, with an overall average of $8.1 \mathrm{mg} \mathrm{cm}^{-3}$. In the model calculations, a value of 8.0 was used for all age groups.

The magnitude of a BMI value in March of Year $n$ (of any group of 2 yr old individuals) did not predict that in

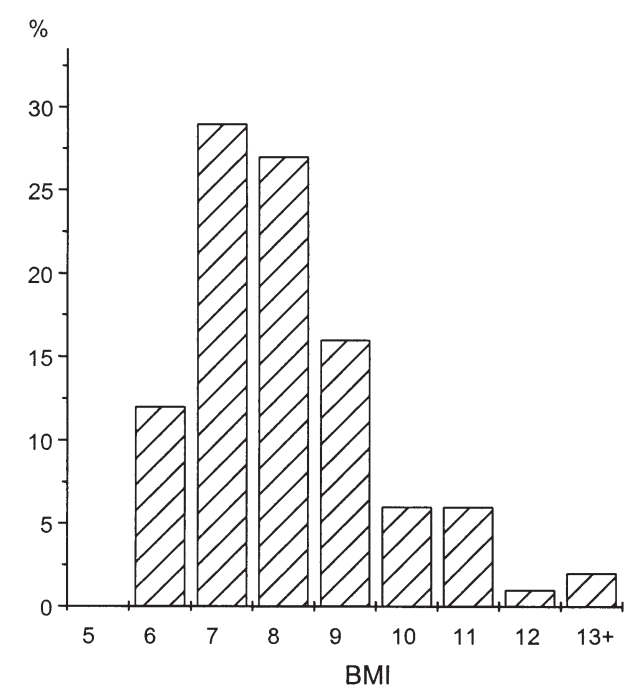

Fig. 2. Macoma balthica. Frequency distribution (\%) of bodymass index, BMI (AFDW of soft parts in mg divided by third power of shell length in $\mathrm{cm}$ ) of $2 \mathrm{yr}$ old individuals in annual samplings in late winter or early spring (mostly in March) during 1970 to 1999 period at 13 stations at Balgzand $(\mathrm{n}=379$, mean $=8.07$, standard deviation $=1.59$ and standard error $=$ $0.08 \mathrm{mg} \mathrm{cm}^{-3}$ ) 

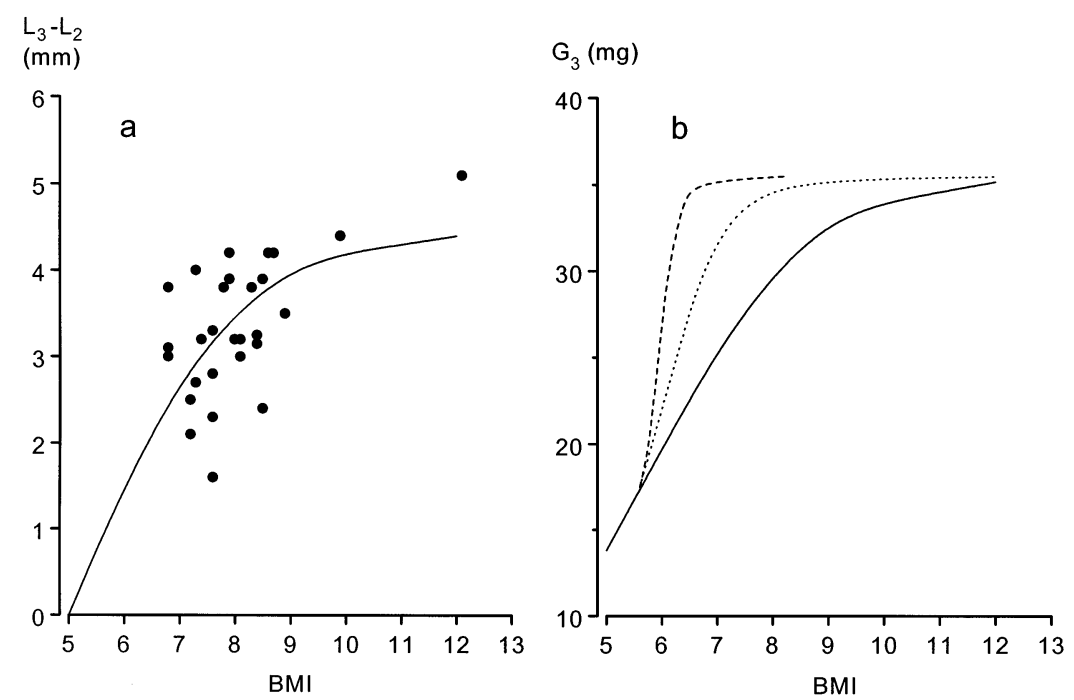

Fig. 3. Macoma balthica. (a) Statistically significant $(p<0.01)$ positive relationship between BMI $\left(\mathrm{mg} \mathrm{cm}^{-3}\right)$ at start of growth season (March, at age $=2 \mathrm{yr}$ ) and subsequent annual length increment $\left(L_{3}-L_{2}\right)$ of shells at Balgzand (in mm, 13-station averages). Each data point represents 1 of the 28 yr from 1970 to1998. Line is best fit drawn by eye. (b) Continuous line shows relationship between pre-spawning BMI (March estimates at age $=2 \mathrm{yr}$ ) and body weight $1 \mathrm{yr}$ later $\left(G_{3}\right.$ in $\mathrm{mg}$ AFDW), calculated from smoothed relationship shown in (a) and applied to standard individual with initial shell length of $12 \mathrm{~mm}$ and BMI of $8 \mathrm{mg} \mathrm{cm}^{-3} 1$ yr later. Two additional (broken) lines were derived from continuous line, and show the relationship of similarly calculated weights with (virtual) post-spawning BMIs. See text 'Results: Survival' for explanation

Year $n+1$ in the same group of then 3 yr old individuals (the $\mathrm{r}^{2}$ values for the 13 stations did not exceed 0.2 ). The model calculations ignore such weak relationships and assume that in any year the mean BMI value arose independently from that in the foregoing year.

\section{Weight-at-length and growth rate}

As both BMI values and growth rates were higher than the long-term average in years that began with a cold winter or were characterized by high food supply, there was a positive relationship between BMI at the start of the growing season and the subsequent length increments (Fig. 3a). The correlation was statistically significant (Spearman's $\mathrm{r}=+0.54, \mathrm{n}=29, \mathrm{p}<0.01$ ). The curve showing the smoothed relationship in Fig. 3a has been drawn by eye and involves some extrapolation at low BMI values. Unfortunately, annual mean values of BMI $<6.9 \mathrm{mg} \mathrm{cm}^{-3}$ were not observed in any of the $29 \mathrm{yr}$ of observation. As a result, it is difficult to judge the validity of the rate at which growth declines with decreasingly low BMI values. The few data available for local groups of individuals with very low BMI points to somewhat higher growth rates than indicated by the line in Fig. 3a. Because few individuals survived in those groups that began the year with a low BMI value (see Fig. 4b), these few data lack precision. If anything, we may have underestimated growth in those individuals that started with very low BMIs in our model calculations.

The relationship of BMI and subsequent growth in length in Fig. 3a can be used to estimate the effect of initial BMI on annual weight increment and on body weight 1 yr later (on the following spawning occasion) in an individual that was of standard size at the start of the year. The resulting estimates of body weight just before the second spawning are shown as a continuous line in Fig. 3b. Such weightunit estimates are required for the model calculations. Two broken lines have been added to Fig. $3 \mathrm{~b}$ to relate these calculated weights also to (virtual) post-spawning BMI values (instead of the actually measured prespawning values). These additional lines are necessary for the model calculations, viz. to include estimates on the results for growth of a range of combinations of BMI and spawning outputs, part of which were not actually observed, but were nevertheless included in the model calculations to show a complete picture of the consequences with all conceivable combinations. See below ('Survival') for a more detailed explanation.

\section{Survival}

During the 20 yr period 1972 to 1991, annual (March to March) survival in 2 yr old Macoma balthica ranged from 41 to $69 \%$ on Balgzand (calculated from the total numbers at the 13 stations used). The $19 \mathrm{yr}$ mean was $58.4 \%$ (SD = 6.9). Annual survival (Fig. 4a) was significantly positively correlated with the Balgzand-mean BMI values at the start of the year: Spearman's $r=$ $+0.56, \mathrm{n}=19, \mathrm{p}<0.02$ ). In older age groups, similar positive relationships were observed between BMI and subsequent survival.

For the total of 13 stations, no mean values of BMI outside the range 6.9 to $8.7 \mathrm{mg} \mathrm{cm}^{-3}$ were observed in any of the $19 \mathrm{yr}$ of observations at Balgzand. Therefore, to obtain estimates of annual survival for groups of very lean and very fat individuals, numerical densities of all separate $13 \times 19$ groups of $2 \mathrm{yr}$ old $M$. balthica were allotted to a range of BMI classes. These had a 
survival rates

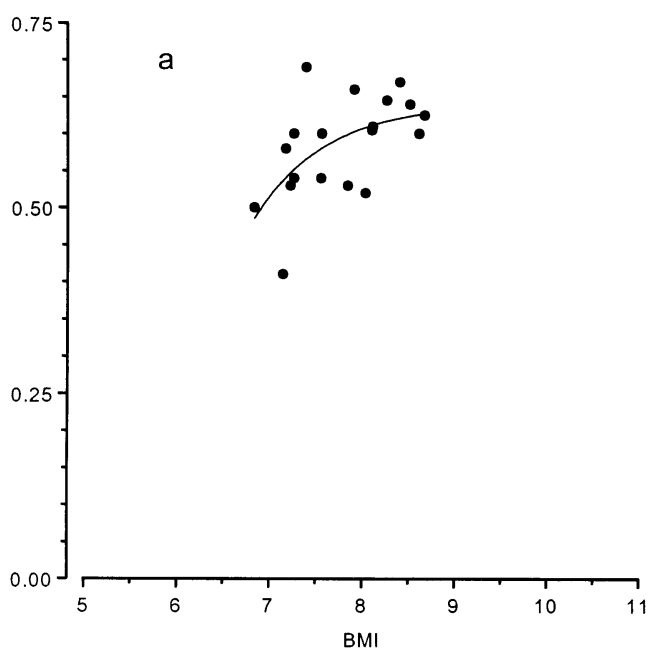

survival rates

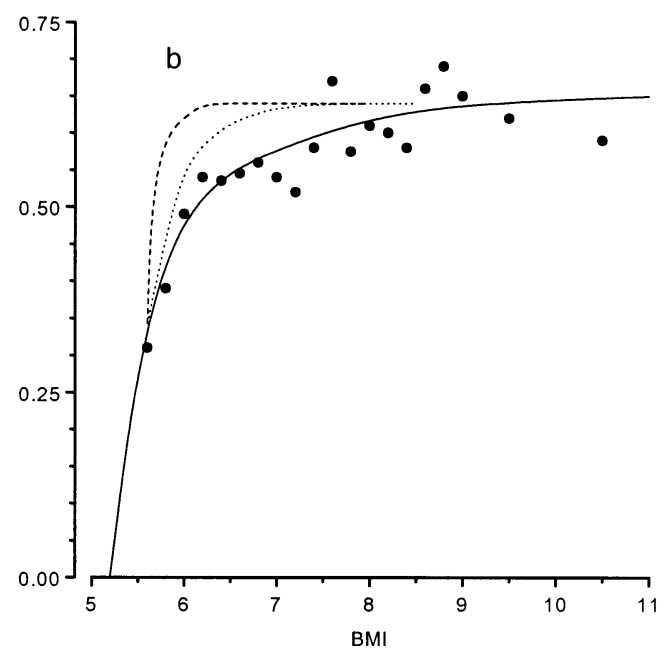

Fig. 4. Macoma balthica. (Data points and continuous lines) Statistically significant $(\mathrm{p}<0.02)$ positive relationship between prespawning BMI (AFDW of soft parts divided by third power of shell length) and the proportions of 2 yr old individuals surviving to subsequent spawning occasion 1 yr later. Lines fit by eye. (a) Weighted 13-station means representing each of the 19 yr from 1972 to 1991; (b) weighted means after allotting the same $19 \times 13$ data pairs to 20 different BMI classes. Additional (broken) lines were derived from continuous line as in Fig. $3 \mathrm{~b}$

width of 0.2 BMI units, but the low numbers of observed BMI values >9 were combined into wider classes of $1.0 \mathrm{mg} \mathrm{cm}^{-3}$. We did not combine classes with low BMIs because we particularly needed estimates of the rate of decline in survival during years that began with very low BMI values.

For each of the 20 BMI classes thus obtained, subsequent survival was estimated from added numerical densities. In this way, weighted survival estimates were calculated for each of the above-defined BMI groups and a relationship between BMI and survival could be assessed without excessive extrapolation (Fig. 4b). As a consequence of the weighting procedure, no standard deviations or standard errors could be given in Fig. 4. Survival was strongly related to initial BMI (Fig. 4b: continuous line). The higher the BMI value at the start of the year, the better the subsequent annual survival (Spearman's $\mathrm{r}=+0.73, \mathrm{n}=20, \mathrm{p}<$ 0.01). The best-fitting line suggests zero survival at BMI $<5.2 \mathrm{mg} \mathrm{cm}^{-3}$, whereas survival remains at an almost constant level of about $64 \%$ in groups that began with higher-than-average (>8) BMI values.

The continuous line in Fig. 4b shows the dependence of survival on pre-spawning BMI. However, for the model calculations of the effects of spawning output on subsequent survival, we needed a relationship between post-spawning BMI and subsequent annual survival. To obtain such relationship, weight loss arising from spawning was expressed in BMI units and subtracted from the pre-spawning BMI values. Thus, the dashed and dotted lines are located to the left of the continuous line in Fig. 4b. The dotted line (closest to the continuous line) represents simply the weight losses at spawning (using BMI-dependent spawning efforts shown in Fig. 5), whereas the dashed line on the far left represents a decline that is $50 \%$ larger than this simple weight loss. The 2 broken lines were used in different versions of the model. The extra (dashed) line for BMI decreases of 1.5 times weight losses is included in Fig. 4b because the energy loss through spawning exceeds weight loss for the following reasons: energy value of eggs is higher than that of other

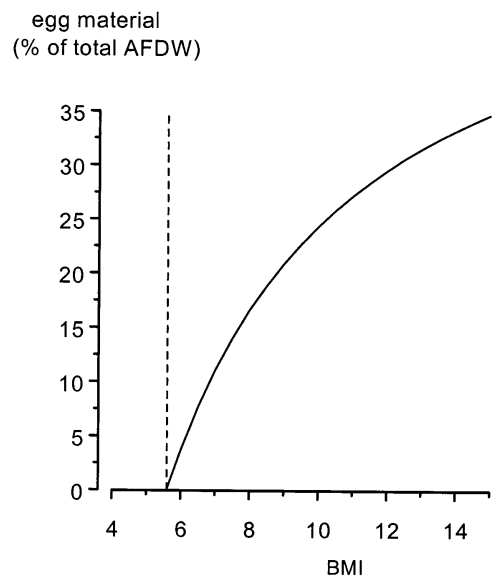

Fig. 5. Macoma balthica. Relationship between pre-spawning BMI, and reproductive investment (expressed as a percentage of AFDW of soft body parts) in adult females. Adapted from Fig. 1B of Honkoop et al. (1999) 
tissues (see below), extra egg production will require extra energy for chemical transformation, and more eggs will mean also more non-egg gonad tissue (socalled overhead costs, cf. Honkoop et al. 1999). Note that the 2 broken lines show only virtual relationships, which were needed for the model calculations but which did not really exist, since in reality the bivalves would also have shown some somatic growth between the time of assessment of pre-spawning BMI and the time of spawning.

\section{Egg production}

On the tidal flats of the Wadden Sea, most Macoma balthica spawn during April (de Wilde \& Berghuis 1978, J.D. \& P.J.C.H. pers. obs.). According to detailed measurements by Honkoop \& van der Meer (1997) of the numbers and sizes of eggs spawned by adult $M$. balthica females, spawning output depends on the dry wt of their soft parts and on their weight-at-length (in BMI units). Honkoop \& van der Meer found the following relationship between number of eggs spawned per individual female (standard length $=15 \mathrm{~mm}$ ) and bodymass index: $\mathrm{n}=7739 \times \mathrm{BMI}-43314$. This equation was found to apply both to females collected just before spawning in the field (at Balgzand) and to females subjected in experiments to various regimes of temperature and food supply (to obtain females with extreme BMI values). It implies that no eggs are spawned by females with a BMI of $5.6 \mathrm{mg} \mathrm{cm}^{-3}$ (viz. $43314: 7739=$ 5.6) or lower. Per BMI unit of $>5.6$, a $15 \mathrm{~mm}$ female spawns an average of 7739 eggs.

Egg numbers are easily converted to egg-mass weights, since there is little variability in egg size in Macoma balthica and the slight variation in egg diameter that does occur is not correlated with the prespawning BMI (Honkoop \& van der Meer 1997). Expressed in weight units, the egg mass spawned per individual (standard-length) female increases from 0 at BMI values $<5.6$ to 10 to $15 \mathrm{mg}$ at $\mathrm{BMI}$ values $>11$ (see Fig. 1A in Honkoop et al. 1999). As a proportion of the total soft-body mass before spawning, the spawned egg mass increases over this BMI range from 0 to $\sim 30 \%$ and amounts to $\sim 16 \%$ of AFDW at an average BMI value of $\sim 8$ (Fig. 5). Thus spawning at this average effort would cause a decrease of BMI amounting to $0.16 \times 8=1.3 \mathrm{mg} \mathrm{cm}^{-3}$.

At 3 intertidal stations in the Wadden Sea, the prespawning weights of dissected gonads were obtained in late March 1999. They were expressed in BMI units to allow for differences in shell length. Such recalculated mean gonad weights increased with increasing total (somatic + gonad) BMI values from 0.9 at $\mathrm{BMI}=$ 7.1 to 1.3 at $\mathrm{BMI}=10.4$ and to 2.3 at $\mathrm{BMI}=13.3 \mathrm{mg}$ $\mathrm{cm}^{-3}$. By late April when most spawning had been completed, gonad weights were again measured. They had substantially declined by average values of 0.6 , 1.1 , and $1.3 \mathrm{mg} \mathrm{cm}^{-3}$, respectively. In accordance with the positive relationship shown in Fig. 5, the mean weight losses of the gonads were greater for high than for low initial BMIs, although in 1999 they were somewhat below the values predicted by the relationship of Honkoop \& van der Meer (1997). The difference may be due to the fact that Honkoop \& van der Meer induced their experimental females to complete spawning and thus included data of only completely spent females, whereas our field data included females that were not spent by late April. Further details on the seasonal changes in gonad weights will be reported by Drent (unpubl. data).

Expressed as energy, the reproductive output (as a proportion of the total soft body) is even higher than when expressed as BMI, since eggs contain more fat than somatic tissue (32 vs $7 \%$ : Beukema \& de Bruin 1977, Honkoop et al. 1999), and as a consequence calorific values of Macoma balthica eggs exceed those of somatic material by $\sim 22 \%$.

\section{Model calculating lifetime egg production}

\section{Assumptions and principles of calculations}

We calculated expected lifetime egg production (mg adult female ${ }^{-1}$ ) for $2 \mathrm{yr}$ old Macoma balthica (i.e. beginning from their first spawning). These calculations were performed separately over a range of combinations of pre-spawning BMI conditions (ranging from 6 to $12 \mathrm{mg} \mathrm{cm}^{-3}$ ) and levels of spawning production at first spawning (ranging from 0 to $n \%$ of total soft-body weight, where $n=$ the highest effort at the given BMI state, i.e. the effort resulting in 0 survival).

Model individuals were exactly $1.2 \mathrm{~cm}$ long at their first spawning (close to the Balgzand average at this age, see continuous line in Fig. 1). Their total prespawning AFDWs ranged from $10.4 \mathrm{mg}$ (at BMI =6) to $20.7 \mathrm{mg}$ (at BMI = 12), calculated as BMI $\times 1.2^{3}$. Spawning output increased step-wise (mostly by 5 or $10 \%$ ) from 0 to a value at which none of the females would survive to the next spawning season (because the effort would result in a post-spawning BMI of 5.2, resulting in 0 survival, see Fig. 4 b). For example, the highest output applicable for a female with a prespawning BMI of 10 was $48 \%$, because $(1.00-0.48) \times$ $10=5.2$. With such an output, the calculated first spawning would amount to $0.48 \times 10 \times 1.2^{3}=8.3 \mathrm{mg}$. This would also represent the lifetime output, since no female expending such high effort would survive to a second spawning. For lower initial outputs, the first 
output would be lower, but would be followed in subsequent years by further outputs by a certain (BMIdependent) proportion of the females. The following example shows how such later outputs were calculated.
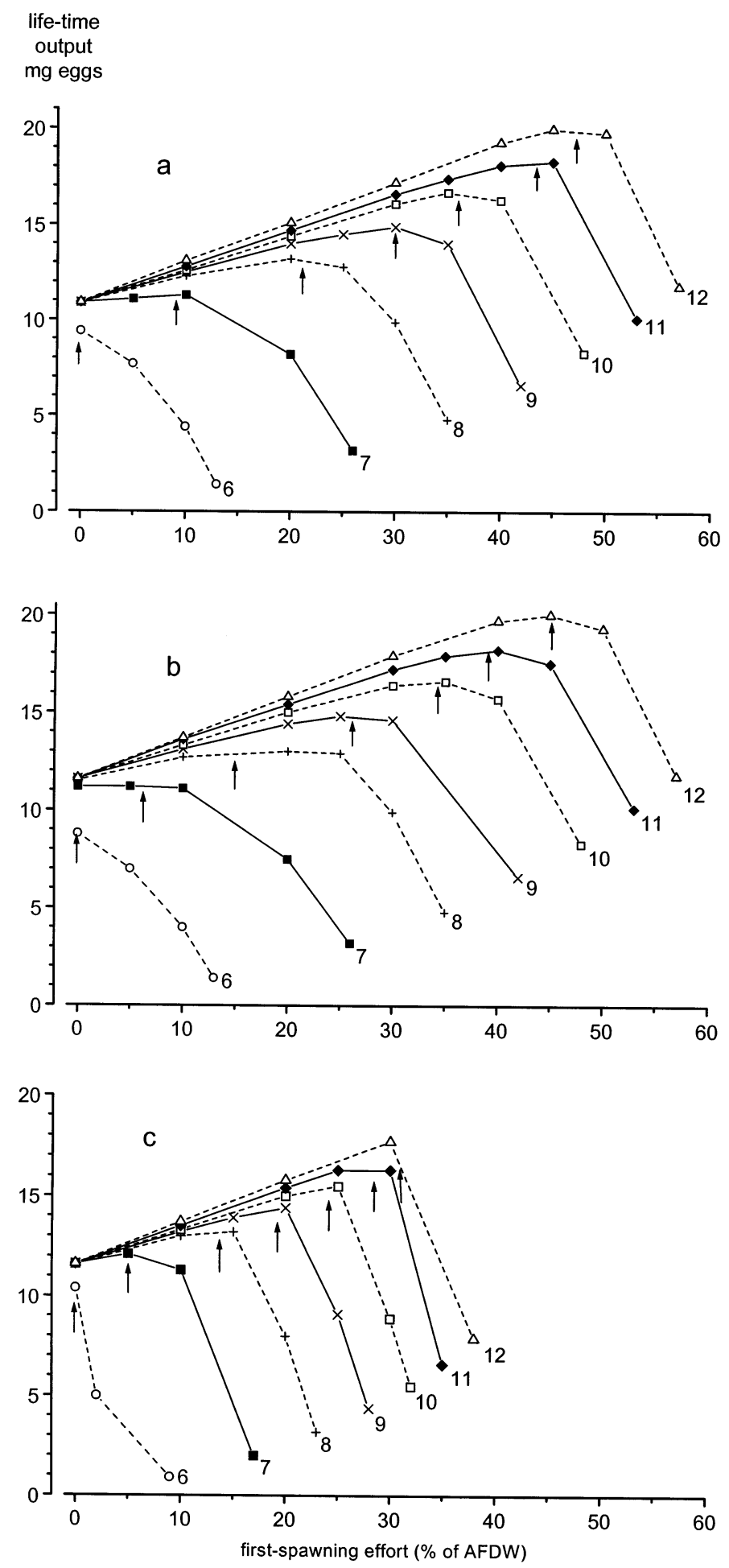

For a first-spawning output of, e.g., $30 \%$ in a $10-\mathrm{BMI}$ female (yielding a first output of $0.30 \times 10 \times 1.2^{3}=$ $5.2 \mathrm{mg}$ ), the post-spawning BMI decreases to 7.0 in the simple-model versions ( $a$ and $b$ ), resulting in a survival of $64 \%$ to the second spawning (Fig. $4 \mathrm{~b}$ : dotted line). In the simple-model version (Version a), BMI effects on growth are neglected (they are included in Versions b and $c_{\text {, }}$ see below), and all individuals grow to a length of $1.55 \mathrm{~cm}$ (as in Fig. 1) at the second spawning. To simplify calculations, we further adopted fixed values for both BMI and reproductive output on second and later spawning occasions $(\mathrm{BMI}=8$, output $=16 \%$; i.e. close to the average values for the Balgzand population: Figs. $2 \& 5$ ). These simplifications appear to be warranted, as it has been shown (above) that BMI values in subsequent years are not related to BMI at first spawning. Thus, at second spawning a 10-BMI female has a weight of $8 \times 1.55^{3}=30 \mathrm{mg}$ and an output of $0.16 \times 30=4.8 \mathrm{mg}$. Subsequent outputs in later years are calculated from subsequent growth increments according to Fig. 1 and a fixed (age-independent) annual survival of $62 \%$ (Beukema 1980, van der Meer et al. 2000). In the simplest-model version (Version a), the total output on the second plus all subsequent spawning occasions depend only on the fraction of females surviving from the first to the second spawning occasion, and amounts to $17 \mathrm{mg}$ per surviving female. For the present 10-BMI female it would amount to $17 \times 0.64=10.9 \mathrm{mg}$, yielding a total lifetime output of 5.2 (first spawning) +10.9 (subsequent spawnings) $=16.1 \mathrm{mg}$ (the value in Fig. $6 \mathrm{a}$ as the $30 \%$ first-output for a BMI = 10 ind.). The other values in Fig. 6a were calculated similarly and show that higher initial BMI values invariably result in higher lifetime outputs for the same first effort, and that higher efforts for the same initial BMI result in higher outputs only up to a certain optimal effort, and thereafter decrease

Fig. 6. Macoma balthica. Results of model calculations (a, b, and $\mathrm{c}$ represent 3 different versions of the model, see: 'Results: Model calculating lifetime egg production'). Total lifetime egg production (expressed in mg AFDW, per female) was calculated for females in different conditions (BMI) at first spawning (indicated by the numbers 6 to 12 in each graph) and (horizontal axis) at increasing levels of spawning effort at first spawning (expressed as \% AFDW lost at spawning). The curves representing lifetime outputs initially increase with increasing effort (since the increasing amounts of eggs produced at the first spawning occasion dominate differences in total lifetime egg production), but steeply decline at higher efforts, a consequence for total egg production of lower subsequent survival and growth (reducing chances and magnitude of further spawning outputs to such an extent that lifetime output becomes smaller). As a result, for any 1 condition (i.e. for any line in the 3 graphs) there is an optimal firstspawning effort in which lifetime output will be maximal. Arrows indicate these optimal values 


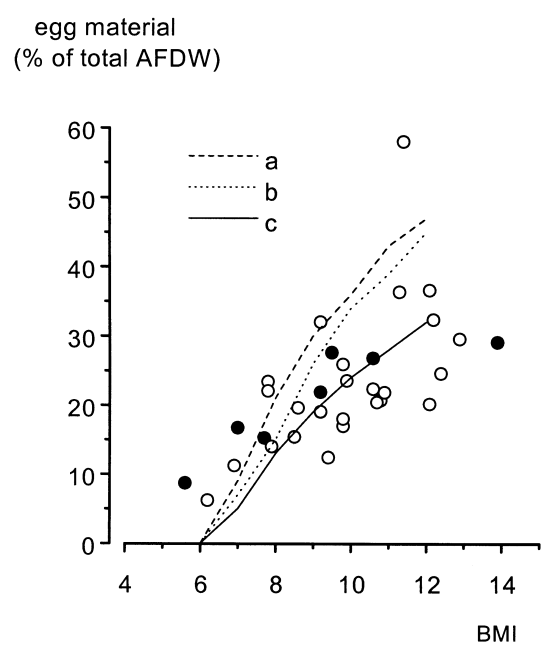

Fig. 7. Macoma balthica. Relationship between weight-atlength (BMI units) and spawning output expressed as a proportion (\%) of AFDW of soft parts. Data points represent actual observations calculated from data in Honkoop \& van der Meer (1997) (O) and in de Wilde \& Berghuis (1978) (•). The 3 lines $(a, b, c)$ represent results of model calculations of how maximum lifetime egg production is achieved; they represent 3 versions of the model with different assumptions on the relationships between BMI at first spawning and subsequent survival and growth (viz. points indicated by arrows in Fig. 6)

with increasing initial effort. Optimal first-spawning outputs were calculated with a precision of $1 \%$, and are indicated by arrows in Fig. 6. They were consistently higher at high than at low initial BMI values (Fig. 6a).

\section{Other versions of the model}

A more refined version of the model (Version b) included not only differential BMI-dependent survival rates but also growth rates between the first and second spawnings, resulting in different body weights at the second spawning (Fig. 3b: dotted line). Compared to the outcome of the simple-model version (Fig. 6a), Version b (Fig. 6b) results in slightly lower values for lifetime egg production at initially low BMIs and slightly higher egg production at initially high BMIs. However, the differences (Version a: Fig. 6a; Version b: Fig. 6b) are only minor. Another difference between these 2 versions refers to the exact position of the arrows in Fig. 6 indicating at which first-spawning effort the maximum lifetime egg production is reached at each BMI. With Version b (Fig. 6b) this effort is slightly lower for the same BMI than with Version a (Fig. 6a). Again, the differences are minor.

A third version (Version c), applying probably more realistic assumptions than Versions $a$ and $b$, included not only BMI-dependent survival and growth (as in Version b), but also a stronger decrease in pre-spawning to post-spawning BMI values than the other versions, i.e. instead of equalling the weight loss through spawning the decreases in BMI were assumed to be 1.5 times such weight loss to allow for extra energy losses (see last paragraph of the earlier subsection 'Survival'). To calculate the annual survival and growth in Version c after first spawning, the dashed lines in Figs. $3 b$ \& 4 b were used, since they represent the strongest decrease (1.5 times weight loss) in BMI at any spawning effort. The lifetime egg productions estimated by Version c were substantially lower, particularly at relatively high first-spawning outputs, than in Versions a and b (cf. Fig. 6c with Fig. 6a,b). The range of first-spawning efforts studied was smaller, as the maximum output at which no further survival to a second spawning takes place occurred at a lower effort than in Versions a and b. The first-spawning efforts at which maximum lifetime output could be realized (arrows in Fig. 6c) were much lower than in the earlier versions of the model (arrows in Fig. 6a,b located more to the right).

\section{Verification of the various versions of the model}

A set of first-spawning combinations of BMI and effort at which lifetime egg production would be maximum (data points arrowed in Fig. 6) comprises the main result of the model calculations. These predictions of optimal spawning effort at each BMI are depicted by the lines in Fig. 7, the 3 lines representing the 3 model versions.

All 3 versions predict a steep increase in optimal first-spawning output with increasing pre-spawning BMI (Fig. 7). To achieve maximum lifetime gamete output, a female should not spawn at a BMI of $<6 \mathrm{mg}$ $\mathrm{cm}^{-3}$ and should increase her efforts with increasing BMI almost linearly to reach (at the high BMI of 12) an egg output of $\sim 45 \%$ of total soft-body weight (according to Versions a and b) or of $\sim 30 \%$ (Version c).

To judge whether these predictions are realistic and which version of the model is the most realistic, we compared them with actual observations on spawning output for various BMIs. Such data are available from 2 studies on egg production in Macoma balthica in the western Wadden Sea. The recalculated values taken from the bottom part of Table 1 of de Wilde \& Berghuis (1978) are shown as black data points in Fig. 7, and (slightly extended) data from Fig. 1B of Honkoop et al. (1999) are shown as open data points. In both studies, egg masses were estimated from repeated spawning stimulation of individual females and a final check for complete emptiness of gonads. Honkoop et al.'s data are for females with 
a shell length of 14 to $17 \mathrm{~mm}$, de Wilde \& Berghuis' data for females of between 16 and $22 \mathrm{~mm}$. These shell lengths were not correlated with BMI $(r=0.11)$ nor with spawning output expressed as a proportion of AFDW ( $\mathrm{r}=$ $0.03)$, and were therefore used indiscriminately.

There is a clear similarity between our model results and the 2 sets of actual observations (Fig. 7). For both model and actual observations, spawning output as a percentage of body weight increases with increasing BMI over a roughly similar range of BMIs. The most complicated model (Version c) shows the best fit with the actual observations. Version c used a factor of 1.5 to convert weight loss by spawning to decrease of BMI. There are valid arguments why this factor should exceed 1.0 (see last paragraph of 'Results: Survival') or even 1.22 (the ratio of the calorific values of eggs and somatic tissue), but the figure of 1.5 was chosen arbitrarily. Had a lower value (between 1.22 and 1.5) been chosen, the position of the continuous line in Fig. 7 would have been slightly higher (but well below the broken lines). On the other hand, a higher value than 1.5 would have resulted in a lower position of this line; however, we see no reason for using a value $>1.5$.

\section{Extension of the model to other size groups and to males}

The model was constructed to elucidate the consequences of variation in gamete output at first spawning at a shell length $1.2 \mathrm{~cm}$. The actual observations shown in Fig. 7 are for larger individuals (mostly 14 to $17 \mathrm{~mm}$ ). Because annual survival does not change with age after $1 \mathrm{yr}$, and because the BMI affected survival in similar ways in all age groups in the Balgzand Macoma balthica population, we would expect a similar relationship between BMI and optimum gamete production for all age groups. Indeed, the positions of the data points in Fig. 7 relative to those of the curves did not differ between small (probably first-time spawning) and larger females. It was thus justifiable to use all available data in the verification of the model.

Although we based all calculations on egg production, we assume that males are producing similar amounts of gametes. In Wadden Sea Macoma balthica, we did not observe sex-dependent differences in gonad weights, nor did Harvey \& Vincent (1989) observe differences in sexual-product weights between male and female $M$. balthica in the St. Lawrence estuary. Thus, although only eggs were used in the calculations of gamete output, the results are presumed to apply to both sexes. The data on survival and growth did not distinguish between sexes. All calculations were based on roughly equal numbers of males and females, since 1:1 sex ratios are typical in $M$. balthica.

\section{DISCUSSION AND CONCLUSIONS}

In Wadden Sea Macoma balthica, annual gamete output is governed by their pre-spawning condition: more eggs are spawned at higher weight-at-length than at lower weight-at-length (Fig. 7). It is not unusual in bivalves for spawning output to be lower for individuals in poor than for individuals in good condition. In the blue mussel Mytilus edulis, Bayne et al. (1978) observed that fewer and smaller eggs were spawned under stress (negative scope for growth). In the $M$. balthica population we studied, only the number of eggs varied.

Year-to-year variability in pre-spawning condition (BMI) in Wadden Sea Macoma balthica will result in particular from differences in feeding and temperature conditions during the preceding winter. Individuals with high BMI (well above 10 and up to 14) can be obtained by keeping them over winter at low temperatures in good feeding conditions, whereas individuals with low BMI can be obtained by keeping them at relatively high winter temperatures and with restricted daily feeding times (Honkoop \& Beukema 1997). In the field, high BMI values were observed in some years. BMIs were especially high in March 1991, after a winter in which there were exceptionally high phytoplankton concentrations in the western Wadden Sea (Beukema \& Cadée 1996). Low values were found occasionally at various stations and in various years, but tended to occur more frequently in the early 1970s than in later years. In the early 1970s, phytoplankton concentrations in the western part of the Wadden Sea were lower than in later years (Beukema \& Cadée 1991, Cadée 1992). BMI further tended to be higher at the end of cold than mild winters (Honkoop \& Beukema 1997). As expected from these relationships with year-to-year differences in winter temperature and food supply, an ANOVA of 30 (yr) $\times 13$ (stations) observations revealed that year-to-year variability explained more $(43 \%)$ of the total variance than station-to-station variability (20\%).

The present results clarify why Macoma balthica tunes gamete output to weight-at-length in the way roughly shown in Fig. 5: according to the models, this strategy ensures maximum lifetime gamete output. In all versions of the model, the optimal output at first spawning increased with increasing BMI, and decreased to 0 at low BMI values of $\sim 6$ (viz. where the lines in Fig. 7 cross the horizontal axis). Increased mortality risks (Fig. 4) as well as slower growth rates (Fig. 3) resulting from low condition contributed to the relationship between BMI and optimal first-spawning effort. However, the influence of survival appears to be more important than that of growth rate, as the 2 broken lines in Fig. 7 differ but slightly (the upper line 
includes effects of differential survival only, the lower line the effects of differences in both survival and growth). Thus, the background of the trade-off between immediate and later spawning is that a too-high initial spawning effort reduces further spawning output, in particular by reducing survival to later spawnings. Although to a lesser extent, body weight on further spawning occasions is also reduced, resulting in slightly lower gamete output on future spawning occasions. Individuals that diverge too greatly from the effort predicted by the model for a given BMI will have a lower lifetime output and thus a lower fitness. If they spawn too many eggs at a low BMI, they have a low chance of survival to a subsequent spawning (see steep initial portion of the survival curves in Fig. 4b). If they spawn too few eggs at a high BMI, they cannot compensate on later spawning occasions (note the flat course of the right-hand parts of the survival and growth curves in Figs. $4 \mathrm{~b} \& 3 \mathrm{~b}$, respectively). Thus, for each weight-at-length (condition) there is an optimal first-spawning gamete output that ensures a maximum lifetime output.

The satisfactory fit of the continuous line in Fig. 7 with the actual observations of 2 independent studies indicates that Version $\mathrm{c}$ of the model more realistically reflects the spawning tactics of the Macoma balthica population than either of the other 2 versions. Version c differs in that it incorporates a greater decrease in BMI at spawning than that based on weight loss alone. Such greater weight loss will be real, because of the known high energy content invested in the eggs and because of the 'overhead' costs involved in gametogenesis.

In the studied Wadden Sea population of Macoma balthica, individuals with a BMI of $<6 \mathrm{mg} \mathrm{cm}^{-3}$ were rare (Fig. 2), even in late winter when BMI values reach their annual minimum (Beukema \& de Bruin 1977). This may be due not only to the high mortality of such lean $M$. balthica, but also to the fact that $M$. balthica actively avoid such low condition states by refraining from energy-expensive gamete production well before a too low BMI is reached. For the purpose of our study this was unfortunate, in that we could collect but few data on individuals with low BMIs and could not precisely assess the left-hand parts of the growth curves in Fig. 3 or of the survival curves in Fig. 4.

If other Macoma balthica populations than the studied Balgzand population show a similar dependence of optimal spawning effort on BMI in spring, this season cannot everywhere be an important spawning season. At the southern edge of the distribution area of $M$. balthica, Hummel et al. (1996) observed low BMI values in April of $\sim 5 \mathrm{mg} \mathrm{cm}^{-3}$ in the estuary of the Gironde (compared to $>10 \mathrm{mg} \mathrm{cm}^{-3}$ in most more northern localities). Individuals with such low BMI values will be at high risk, as indeed reflected by their high mortality under stress (Hummel et al. 1996). Indeed, $M$. balthica living in the Gironde estuary show a retracted spawning season whose timing differs greatly from year to year (Bachelet 1986), apparently in response to year-to-year differences in body weight. Such plasticity is adaptive (Bayne 1985), since it enables survival during periods of low nutrients and delaying reproductive output to periods when conditions are favourable and body weights sufficiently high. In more northern areas, $M$. balthica populations almost invariably spawn during a short period in spring, although there is some anecdotal evidence of occasionally late spawning in the Wadden Sea (Günther et al. 1998). It would be interesting to determine whether southern $M$. balthica populations (with presumably year-round small scope for growth) produce fewer (and/or smaller) eggs than populations at higher latitudes. The bay scallop provides an example of such latitudinal shifts (Barber \& Blake 1983).

Acknowledgements. We are grateful to Wim de Bruin, Diana Kwast and Jaap Zuidewind for dedicated assistance in the collection and processing of Macoma balthica samples. Wim de Bruin prepared the figures. This project was partly funded by the Netherlands National Research Program (NRP I) Global Change No. 851053. This is Publication No. 3436 of NIOZ, Texel.

\section{LITERATURE CITED}

Bachelet G (1986) Recruitment and year-to-year variability in a population of Macoma balthica balthica (L.). Hydrobiologia 142:233-248

Barber BJ, Blake NJ (1983) Growth and reproduction of the bay scallop, Argopecten irradians (Lamarck) at its southern distributional limit. J Exp Mar Biol Ecol 66:247-256

Bayne BL (1985) Responses to environmental stress: tolerance, resistance and adaptation. In: Gray JS, Christiansen ME (eds) Marine biology of polar regions and effects of stress on marine organisms. Wiley, Chichester, p 331-349

Bayne BL, Holland DL, Moore MN, Lowe DM, Widdows J (1978) Further studies on the effects of stress in the adult on the eggs of Mytilus edulis. J Mar Biol Assoc UK 58: 825-841

Beukema JJ (1980) Calcimass and carbonate production by molluscs on the tidal flats in the Dutch Wadden Sea: I. The tellinid bivalve Macoma balthica. Neth J Sea Res 14: 323-338

Beukema JJ (1993) Successive changes in distribution patterns as an adaptive strategy in the bivalve Macoma balthica (L.) in the Wadden Sea. Helgol Meeresunters 47: 287-304

Beukema JJ, Cadée GC (1991) Growth rates of the bivalve Macoma balthica in the Wadden Sea during a period of eutrophication: relationships with concentrations of pelagic diatoms and flagellates. Mar Ecol Prog Ser 68: 249-256

Beukema JJ, Cadée GC (1996) Consequences of the sudden removal of nearly all mussels and cockles from the Dutch Wadden Sea. PSZN I: Mar Ecol 17:279-289 
Beukema JJ, de Bruin W (1977) Seasonal changes in dry weight and chemical composition of the soft parts of the tellinid bivalve Macoma balthica in the Dutch Wadden Sea. Neth J Sea Res 11:42-55

Beukema JJ, Meehan BW (1985) Latitudinal variation in linear growth and other shell characteristics of Macoma balthica. Mar Biol 90:27-33

Bonsdorff E, Wenne R (1989) A comparison of condition indices of Macoma balthica (L.) from the northern and southern Baltic Sea. Neth J Sea Res 23:45-55

Cadée GC (1992) Phytoplankton variability in the Marsdiep, The Netherlands. ICES Mar Sci Symp 195:213-222

de Wilde PAWJ, Berghuis EM (1978) Laboratory experiments on the spawning of Macoma balthica; its implication for production research. In: McLusky DS, Berry AJ (eds) Physiology and behaviour of marine organisms. Pergamon Press, Oxford, p 375-384

Günther CP, Boysen-Ennen E, Niesel V, Hasemann C, Heuers J, Bittkau A, Fetzer I, Nacken M, Schlüter M, Jaklin S (1998) Observations of a mass occurrence of Macoma balthica larvae in midsummer. J Sea Res 40:347-351

Harvey M, Vincent B (1989) Spatial and temporal variations of the reproductive cycle and energy allocation of the bivalve Macoma balthica (L.) on a tidal flat. J Exp Mar Biol Ecol 129:199-217

Honkoop PJC, Beukema JJ (1997) Loss of body mass in winter in three intertidal bivalve species: an experimental and observational study of the interacting effects between

Editorial responsibility: Otto Kinne (Editor),

Oldendorf/Luhe, Germany water temperature, feeding time and feeding behaviour. J Exp Mar Biol Ecol 212:277-297

Honkoop PJC, van der Meer J (1997) Reproductive output of Macoma balthica populations in relation to winter-temperature and intertidal-height mediated changes of body mass. Mar Ecol Prog Ser 149:155-162

Honkoop PJC, van der Meer J, Beukema JJ, Kwast D (1999) Reproductive investment in the intertidal bivalve Macoma balthica. J Sea Res 41:203-212

Houston AI, McNamara JM (1999) Models of adaptive behaviour. Cambridge University Press, Cambridge

Hummel H, Amiard-Triquet C, Bachelet G, Desprez M, Marchand J, Sylvand B, Amiard JC, Rybarczyk H, Bogaards RH, Sinke J, De Wit Y, de Wolf L (1996) Sensivity to stress of the estuarine bivalve Macoma balthica from areas between The Netherlands and its southern limits (Gironde). J Sea Res 35:315-321

Lammens JJ (1967) Growth and reproduction of a tidal flat population of Macoma balthica (L.). Neth J Sea Res 3: 315-382

Myrand B, Guderley H, Himmelman JH (2000) Reproduction and summer mortality of blue mussels Mytilus edulis in the Magdalen Islands, southern Gulf of St. Lawrence. Mar Ecol Prog Ser 197:193-207

van der Meer J, Beukema JJ, Dekker R (2001) Long-term variability in secondary production of an intertidal bivalve population is primarily a matter of recruitment variability. J Anim Ecol 69 (in press)

Submitted: April 3, 2000; Accepted: July 4, 2000

Proofs received from author(s): November 27, 2000 